\title{
Where Is the Drug? Quantitative 3D Distribution Analyses of Confined Drug-Loaded Polymer Matrices
}

Mazzoni, Chiara; Tentor, Fabio; Antalaki, Anastasia; Jacobsen, Rasmus D.; Mortensen, Jacob; Slipets, Roman; Ilchenko, Oleksii; Keller, Stephan S.; Nielsen, L. Hagner; Boisen, Anja

\section{Published in:}

A C S Biomaterials Science \& Engineering

Link to article, DOI:

10.1021/acsbiomaterials.9b00495

Publication date:

2019

Document Version

Peer reviewed version

Link back to DTU Orbit

Citation $(A P A)$ :

Mazzoni, C., Tentor, F., Antalaki, A., Jacobsen, R. D., Mortensen, J., Slipets, R., Ilchenko, O., Keller, S. S. Nielsen, L. H., \& Boisen, A. (2019). Where Is the Drug? Quantitative 3D Distribution Analyses of Confined DrugLoaded Polymer Matrices. A C S Biomaterials Science \& Engineering, 5(6), 2935-2941. https://doi.org/10.1021/acsbiomaterials.9b00495

\section{General rights}

Copyright and moral rights for the publications made accessible in the public portal are retained by the authors and/or other copyright owners and it is a condition of accessing publications that users recognise and abide by the legal requirements associated with these rights.

- Users may download and print one copy of any publication from the public portal for the purpose of private study or research.

- You may not further distribute the material or use it for any profit-making activity or commercial gain

- You may freely distribute the URL identifying the publication in the public portal 
Controlled Release and Delivery Systems

Subscriber access provided by DTU Library

\author{
Where is the drug? - Quantitative 3D distribution \\ analyses of confined drug-loaded polymer matrices
}

Chiara Mazzoni, Fabio Tentor, Anastasia Antalaki, Rasmus Due Jacobsen, Jacob Mortensen, Roman Slipets, Oleksii Ilchenko, Stephan Sylvest Keller, Line Hagner Nielsen, and Anja Boisen

ACS Biomater. Sci. Eng., Just Accepted Manuscript • DOI: 10.1021/acsbiomaterials.9b00495 • Publication Date (Web): 10 May 2019

Downloaded from http://pubs.acs.org on May 14, 2019

\title{
Just Accepted
}

"Just Accepted" manuscripts have been peer-reviewed and accepted for publication. They are posted online prior to technical editing, formatting for publication and author proofing. The American Chemical Society provides "Just Accepted" as a service to the research community to expedite the dissemination of scientific material as soon as possible after acceptance. "Just Accepted" manuscripts appear in full in PDF format accompanied by an HTML abstract. "Just Accepted" manuscripts have been fully peer reviewed, but should not be considered the official version of record. They are citable by the Digital Object Identifier (DOI®). "Just Accepted" is an optional service offered to authors. Therefore, the "Just Accepted" Web site may not include all articles that will be published in the journal. After a manuscript is technically edited and formatted, it will be removed from the "Just Accepted" Web site and published as an ASAP article. Note that technical editing may introduce minor changes to the manuscript text and/or graphics which could affect content, and all legal disclaimers and ethical guidelines that apply to the journal pertain. ACS cannot be held responsible for errors or consequences arising from the use of information contained in these "Just Accepted" manuscripts. 


\title{
Where is the drug? - Quantitative 3D distribution
} analyses of confined drug-loaded polymer matrices

\author{
Chiara Mazzoni ${ }^{*+}$, Fabio Tentor ${ }^{+}$, Anastasia Antalaki ${ }^{+}$, Rasmus D. Jacobsen ${ }^{+}$, Jacob \\ Mortensen $^{+}$, Roman Slipets $^{+}$, Oleksii Ilchenko $^{+}$, Stephan S. Keller ${ }^{\diamond}$, L. Hagner Nielsen ${ }^{+}$, Anja \\ Boisen $^{*+}$
}

+ The Danish National Research Foundation and Villum Foundation's Center for Intelligent Drug Delivery and Sensing Using Microcontainers and Nanomechanics (IDUN) - Department of Health Technology, Technical University of Denmark, Ørsteds Plads Building 345C, Kgs. Lyngby, 2800, Denmark

$\diamond$ The Danish National Research Foundation and Villum Foundation's Center for Intelligent Drug Delivery and Sensing Using Microcontainers and Nanomechanics (IDUN) -National Centre for Nano Fabrication and Characterization, Technical University of Denmark, Ørsteds Plads Building 345B, Kgs. Lyngby, 2800, Denmark

* Corresponding authors: chimaz@dtu.dk, anja.boisen@dtu.dk

\begin{abstract}
To enhance oral bioavailability of poorly soluble drugs, microfabricated devices can be utilized. One example of such devices is microcontainers. These are cylindrical in shape with an inner
\end{abstract}


cavity for drug loading and with only the top side open for release. Supercritical $\mathrm{CO}_{2}\left(\mathrm{scCO}_{2}\right)$ impregnation is an interesting technique for loading drugs into polymeric matrices in e.g. microcontainers since it avoids the use of organic solvents and is cheap. One of the main drawbacks of this technique is the unknown three dimensional drug distribution in the polymer matrix. The aim of this study was to investigate the loading of two poorly soluble drugs, naproxen and ketoprofen, by $\mathrm{scCO}_{2}$ impregnation into confined polymer matrices of different sizes. Three different sizes of microcontainers (small, medium and large) and thereby, different surface areas accessible for impregnation, were compared. From in vitro studies, the amount of naproxen and ketoprofen loaded into the different microcontainers and their corresponding release profiles were seen to be similar. A custom-made Raman microscope facilitated volumetric Raman maps of an entire microcontainer filled with polyvinylpyrrolidone (PVP) and $\mathrm{scCO}_{2}$ impregnated with either naproxen or ketoprofen. In all microcontainer sizes, the drugs were only detected in the top layer of the polymer matrix, explaining the observed similar release profiles. Using X-Ray Powder Diffraction and Raman spectroscopy, the solid state form of the drugs was evaluated, showing that ketoprofen was amorphous in all microcontainer sizes. Naproxen was found not to be crystalline neither amorphous, but in a less ordered configuration than the crystalline state. In conclusion, volumetric Raman mapping is a powerful technology for imaging drug distribution and drug crystallinity in polymers and allowed us to conclude that i) $\mathrm{scCO}_{2}$ impregnation depth does not depend on surface area and ii) impregnated drugs are noncrystalline.

KEYWORDS: Microdevices, polymer matrix, drug distribution, poorly soluble drug, supercritical $\mathrm{CO}_{2}$ impregnation, Raman spectroscopy 


\section{INTRODUCTION}

Among the different administration routes for drugs, oral delivery is preferred by patients since the drug can be self-administered leading to high compliance. ${ }^{1}$ However, oral drug delivery is often challenging due to e.g. harsh conditions in the stomach and poor permeability over the intestinal wall. ${ }^{1}$ Many drugs are classified as poorly water soluble in the biopharmaceutics classification system (BCS, class II and IV). ${ }^{2,3}$ For oral delivery of poorly soluble drugs, solubility and dissolution rate need to be improved to obtain an acceptable bioavailability. One approach for achieving this, is to convert the drug to its amorphous form. ${ }^{4}$ Here, the long range order in the crystal lattice is lacking and the disordered structure results in improved solubility and dissolution rate. ${ }^{4,5}$ The disadvantage of the amorphous form is its physical and chemical instability. It can convert back to its metastable or stable counterpart during storage and/or dissolution. ${ }^{6}$ There are various techniques to improve the physical stability of the amorphous form e.g. co-amorphization of two drugs ${ }^{7}$ or use of polymers as excipients. ${ }^{8}$ Another approach for protecting the amorphous drugs is the use of microcontainers. ${ }^{59}$ Microcontainers are cylindrical, polymeric microdevices with an inner cavity for drug loading and with only the top side open. Previously, confinement of the amorphous poorly soluble drug indomethacin reduced the re-crystallization rate by 1.8 fold compared to unconfined bulk samples. ${ }^{5}$ In particular, using microcontainers with cavity diameters of $174 \mu \mathrm{m}, 29.0 \pm 2.6 \%$ of the amorphous indomethacin crystallized over a period of 30 days compared to microcontainers with diameters of $223 \mu \mathrm{m}$ where $38.3 \pm 1.5 \%$ crystallized. This indicates that microcontainers with smaller diameters enhance the stability of the amorphous drug loaded inside. ${ }^{5}$ Unconfined indomethacin crystallized within a few days. In addition to the stabilization properties, microcontainers have been used for improving oral drug delivery by protecting the drug from the harsh gastric 
environment and providing a release in the small intestine. ${ }^{10-12}$ Furthermore, it has been demonstrated that microcontainers adhere to the intestinal mucus layer leading to higher relative oral bioavailability in rats of model drugs such as ketoprofen and furosemide compared to controls. ${ }^{13,14}$

In spite of the advantages of utilizing microdevices for oral drug delivery, loading drugs into the small cavities can be challenging since all of the well-known techniques for preparing oral formulations, such as tableting, cannot be used. Supercritical $\mathrm{CO}_{2}\left(\mathrm{scCO}_{2}\right)$ impregnation is one of the techniques that can be used for loading drugs into polymer-filled microcontainers. The critical point of $\mathrm{CO}_{2}$ is $31.1^{\circ} \mathrm{C}$ and 73.8 bar and due to those mild conditions, this technique is suitable for drug loading. In addition, it can be used in combination with various polymers. ${ }^{15,16}$ It has previously been demonstrated that the hydrophilic polymer polyvinylpyrrolidone (PVP) can be loaded into microcontainers as a polymer matrix and impregnated by $\mathrm{scCO}_{2}$ with the drug ketoprofen. ${ }^{17,18}$ It was found that ketoprofen was in its amorphous form after impregnation in the PVP matrix inside the microcontainers. ${ }^{14}$ However, the influence of the size of the confined polymer volumes loaded by supercritical impregnation has never been investigated. One of the main challenges for systematic studies of drug loading with this technique has been the unknown three-dimensional (3D) drug distribution in the polymer matrix after $\mathrm{CO}_{2}$ impregnation. Therefore, it has not been possible to understand the influence of the parameters on the release profiles and the drug-polymer interactions. ${ }^{16,17,19}$

In literature, the distribution of impregnated or encapsulated material has been studied with various techniques. Polymeric membranes have been examined with energy dispersive X-ray analyses, obtaining a two-dimensional map, ${ }^{19}$ and this technique has also been successfully used for 3D mapping of nanoparticles. ${ }^{20}$ Dispersive X-ray Absorption Spectroscopy ( $\mu$ ED-XAS) 
tomography has been utilized and was able to resolve both 2D and 3D spatial distribution of chemical species from different iron mineral standards. ${ }^{21}$ Alternatively, Raman spectroscopy has been used to evaluate the distribution of a drug inside a 3D printed tablet. ${ }^{22}$ Previously, a 2D map of a cross section of tablets using Raman spectroscopy has been obtained, understanding the distribution of three different components in an area of $4 \times 4 \mathrm{~mm} .{ }^{23}$ Raman spectroscopy has successfully been used as a quantification technique in case of inkjet-printed pharmaceuticals requiring, however, the sectioning of the sample prior to analyses in order to measure a cross section. ${ }^{24}$ Cross sectional mapping with Raman spectroscopy is a destructive method and in case of a confined polymer matrix (i.e. for microcontainers) this application is not possible. Furthermore, for investigations with Raman spectroscopy, the polymer and drug normally have a relatively low transparency under laser excitation. For reaching an acceptable Raman signal at the bottom of samples as deep as e.g. a microcontainer reservoir, a highly sensitive method for confocal Raman microscope has been developed.

The aim of this study was to investigate the loading of two BCS class II drugs, naproxen and ketoprofen, using $\mathrm{scCO}_{2}$ impregnation into confined polymer matrices of different sizes. For this purpose, three different sizes of microcontainers (small, medium and large) and thereby, different surface areas accessible for impregnation were compared. Furthermore, the quantity and solid state form of ketoprofen and naproxen loaded into the microcontainers were evaluated. Finally, the $3 \mathrm{D}$ distribution of the drugs in $225 \mu \mathrm{m}$ deep polymer matrices was analyzed by confocal Raman microscopy.

\section{EXPERIMENTAL SECTION}

\subsection{MATERIALS}


Silicon (Si) wafers (4-in, b100N n-type) were provided by Okmetic (Vantaa, Finland). SU-8 2075 and SU-8 developer were purchased from Microresist Technology GmbH (Berlin, Germany). Polyvinylpyrrolidone (PVP) (Molecular weight of 10,000 Da), ketoprofen powder ( $\geq 98 \%$, racemate) and phosphate buffer saline (PBS) were obtained from Sigma-Aldrich (St. Louis, MO, USA). Naproxen was purchased from Fagron (Newcastle upon Tyne, England). Deionized water $(18.2 \mathrm{~m} \Omega$ ) was acquired from Merck KGaA (Darmstadt, Germany).

\subsection{METHODS}

\subsubsection{FABRICATION OF MICROCONTAINERS}

Squared chips of microcontainers with dimensions of $12.8 \times 12.8 \mathrm{~mm}^{2}$ were fabricated on $\mathrm{Si}$ wafers in the epoxy-based photoresist SU-8 using a similar procedure as described previously. ${ }^{5}$ Three different sizes of microcontainers were produced having three different cavity diameters (small, medium and large) and the same cavity height. The number of microcontainers per chip for the three different sizes was chosen to keep the total polymer surface exposed to the $\mathrm{scCO}_{2}$ per chip constant, and thereby also the total polymer volume constant. The dimensions of the microcontainers were measured using an Alpha-Step IQ Stylus Profilometer (KLA-Tencor Corporation, Milpitas, USA) and an optical microscope.

\subsubsection{LOADING OF NAPROXEN AND KETOPROFEN INTO MICROCONTAINERS USING SUPERCRITICAL $\mathrm{CO}_{2}$ IMPREGNATION}

The microcontainers on Si chips were manually filled with PVP powder. Excess powder in between the microcontainers was blown away using an air gun in a similar setup as described previously. ${ }^{14}$ One chip of each size (small, medium and large) was placed within a supercritical $\mathrm{CO}_{2}$ chamber, together with $4.8 \pm 0.1 \mathrm{mg}(\mathrm{n}=3)$ of ketoprofen powder or $6.0 \pm 0.03 \mathrm{mg}(\mathrm{n}=3)$ of naproxen. The impregnation with ketoprofen was conducted by bringing $\mathrm{CO}_{2}$ to its supercritical 
state at 120 bar and $45^{\circ} \mathrm{C}$ keeping it under stirring for $1 \mathrm{~h}$. The impregnation with naproxen was performed bringing $\mathrm{CO}_{2}$ to 100 bar and $40^{\circ} \mathrm{C}$. These parameters were chosen to have a solubility in the supercritical $\mathrm{CO}_{2}$ of $0.06 \mathrm{~g} / \mathrm{L}$ for both drugs. ${ }^{25,26}$ The pressurization and depressurization rates were $3.9 \mathrm{bar} / \mathrm{min}$ and $2.5 \mathrm{bar} / \mathrm{min}$, respectively, for both drugs. The chips with microcontainers were weighed before and after filling with PVP to determine the amount of polymer loaded into the microcontainers. A tabletop Scanning Electron Microscope (SEM) TM3030Plus (Hitachi High-Technologies, Tokyo, Japan) was used to visualize the microcontainers after filling with PVP and after the impregnation process.

\subsubsection{IN VITRO RELEASE OF KETOPROFEN OR NAPROXEN FROM MICROCONTAINERS}

For determining the release of ketoprofen or naproxen over time, a $\mu$-Diss profiler (pION INC, Woburn, MA), equipped with in situ UV probes with a path length of $10 \mathrm{~mm}$ for ketoprofen and $5 \mathrm{~mm}$ for naproxen was used. The release studies were performed in PBS at pH 6.5 for $120 \mathrm{~min}$. Standard curves of either ketoprofen or naproxen were obtained before each release experiment. In order to prepare the standard curves, aliquots of a stock solution of ketoprofen $(5 \mathrm{mg} / \mathrm{mL}$ in ethanol) or naproxen ( $3 \mathrm{mg} / \mathrm{mL}$ in ethanol) were added to known volumes of $\mathrm{PBS}$, and the absorbance was assessed in a wavelength range of 250-260 nm for ketoprofen and at a wavelength of $230 \mathrm{~nm}$ for naproxen.

For release experiments, the chips with drug-loaded microcontainers were attached to cylindrical magnets and placed inside glass vials. $10 \mathrm{~mL}$ of PBS buffer were added to the vials immediately before starting an experiment. All the release studies were run at $37^{\circ} \mathrm{C}$ stirring the chips at $100 \mathrm{rpm}$. The experiments were performed in triplicates for each drug and for each size 
of microcontainers, the data are presented as mean (normalized by the quantity of PVP filled) \pm SD.

\subsubsection{THREE-DIMENSIONAL DISTRIBUTION OF DRUGS IN MICROCONTAINERS}

Volumetric Raman microscopy was used to evaluate the distribution of ketoprofen or naproxen in the microcontainers. The microscope collected Raman spectra in the range of $350-2400 \mathrm{~cm}^{-1}$ with a spectral resolution of $2.5 \mathrm{~cm}^{-1}$ under the excitation of a $785 \mathrm{~nm}$ laser. The laser power was $35 \mathrm{~mW}$, and the diffraction limited spot size was equal to $1.7 \mu \mathrm{m}$ with the use of a $100 \mathrm{x} / 0.75 \mathrm{HD}$ DIC Zeiss microscope objective. The chip of microcontainers was placed on the surface of a custom-made Peltier stage and kept at $8^{\circ} \mathrm{C}$ during Raman measurements. These Raman spectra were studied performing a non-negative least squares analysis to obtain quantitative chemical response, visualized as voxel based 3D images. ${ }^{27,28}$

\subsubsection{SOLID STATE ANALYSES OF THE DRUGS LOADED INTO} MICROCONTAINERS

X-Ray Powder Diffraction (XRPD) was used to determine the solid state form of ketoprofen or naproxen in the microcontainers. An X'Pert PRO X-ray diffractometer (PANalytical, Almelo, The Netherlands, MPD PW3040/60 XRD; $\mathrm{Cu}$ KR anode, $\lambda=1.541 \AA, 45 \mathrm{kV}, 40 \mathrm{~mA}$ ) was utilized. A starting angle of $5^{\circ} 2 \theta$ and an end angle of $28^{\circ} 2 \theta$ were employed for the scans with a scan speed of $0.67335^{\circ} 2 \theta / \mathrm{min}$ and a step size of $0.0262606^{\circ} 2 \theta$. Data were collected using X'Pert Data Collector software (PANalytical B.V.). The diffractograms of naproxen or ketoprofen loaded in the microcontainers were compared to the pure crystalline drugs. In addition, Raman microscopy was used to investigate the solid state form of the drugs. The spectra measured from the naproxen or ketoprofen loaded into the microcontainers were collected as described in "Three-dimensional distribution of the drugs in microcontainers" 
section. For the spectra of crystalline and amorphous ketoprofen, naproxen and PVP the laser power was $35 \mathrm{~mW}$ and the exposure time was $2 \mathrm{~s}$. The amorphous ketoprofen was prepared by melting the crystalline ketoprofen powder at $98^{\circ} \mathrm{C}$ on a heating plate followed by immediate measurements of the sample.

\subsubsection{STATISTICS}

All data are expressed as mean \pm standard deviation (SD). Statistical analyses were carried out, where relevant, using Student t-tests (GraphPad Prism, La Jolla, CA, USA, version 7.04). Pvalues below $5 \%(\mathrm{p}<0.05)$ were considered statistically significant.

\subsection{RESULTS AND DISCUSSION}

\subsubsection{FABRICATION OF MICROCONTAINERS}

Cylindrical microcontainers with three different sizes were successfully fabricated (Table 1 and Figure 1). The cavity depth of the microcontainers with the different sizes was kept constant at $225 \mu \mathrm{m}$. The number of microcontainers per chip was chosen to keep the total polymer volume and the total surface area exposed to the supercritical $\mathrm{CO}_{2}$ similar for the different sizes (Table 1). Due to this, it was possible to compare the influence of the microcontainer size on quantity and distribution of the poorly soluble model drugs loaded with supercritical $\mathrm{CO}_{2}$ impregnation.

Table 1. Numbers showing the dimensions of the SU-8 microcontainers, amount of microcontainers per chip and total polymer surface area per chip. The data represents mean \pm SD in 8 replicates.

\begin{tabular}{|l|l|l|lr|}
\hline Sample & $\begin{array}{l}\text { Internal } \\
\text { microcontainer } \\
\text { diameter }[\mu \mathrm{m}]\end{array}$ & $\begin{array}{l}\text { Number of } \\
\text { microcontainers } \\
\text { per chip }\end{array}$ & $\begin{array}{l}\text { Total area } \\
\text { surface axper to } \mathrm{scCO}_{2} \\
\text { exposed } \\
\text { per chip }\left[\mathrm{mm}^{2}\right]\end{array}$ \\
\hline
\end{tabular}




\begin{tabular}{|l|l|l|l|} 
Small & $97 \pm 6$ & 1024 & $31 \pm 4$ \\
\hline Medium & $191 \pm 9$ & 256 & $30 \pm 3$ \\
\hline Large & $413 \pm 5$ & 64 & $34 \pm 1$ \\
\hline
\end{tabular}
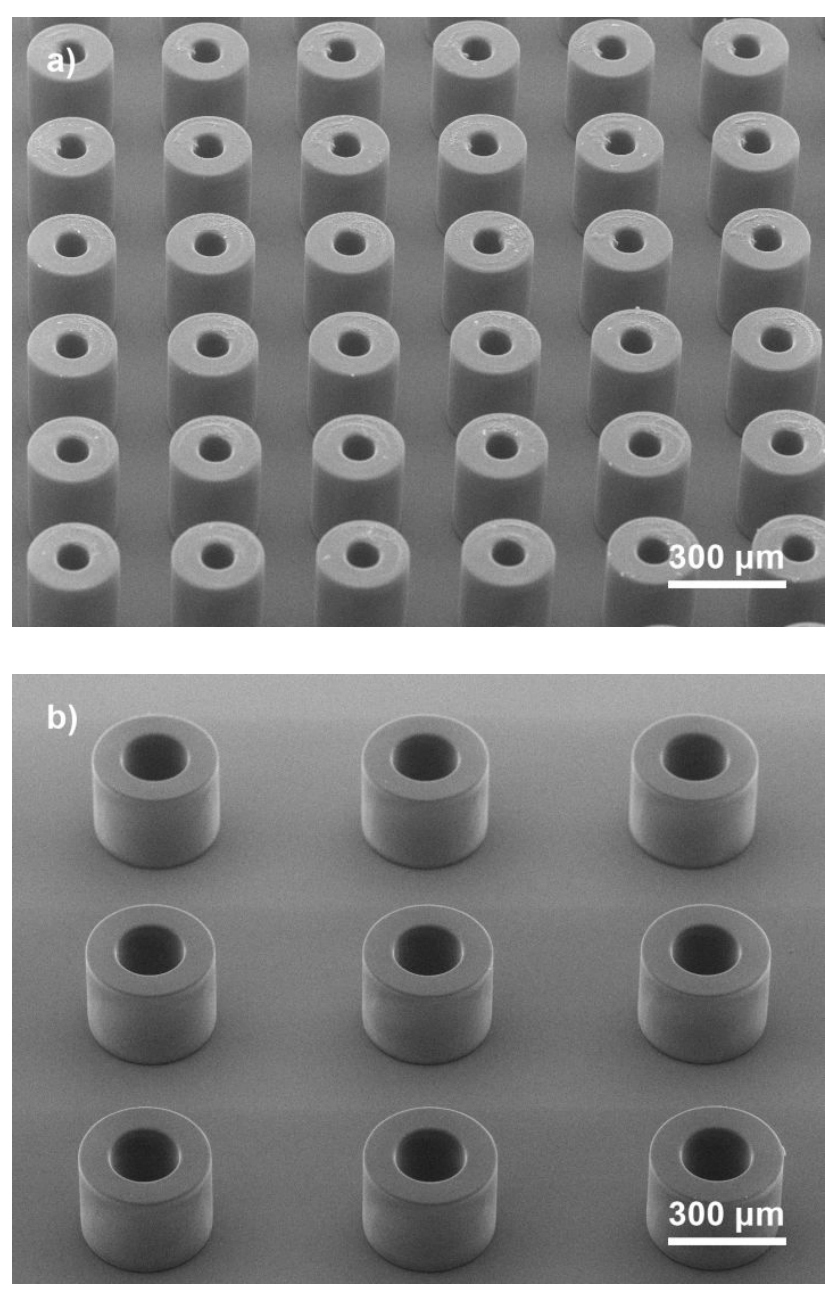


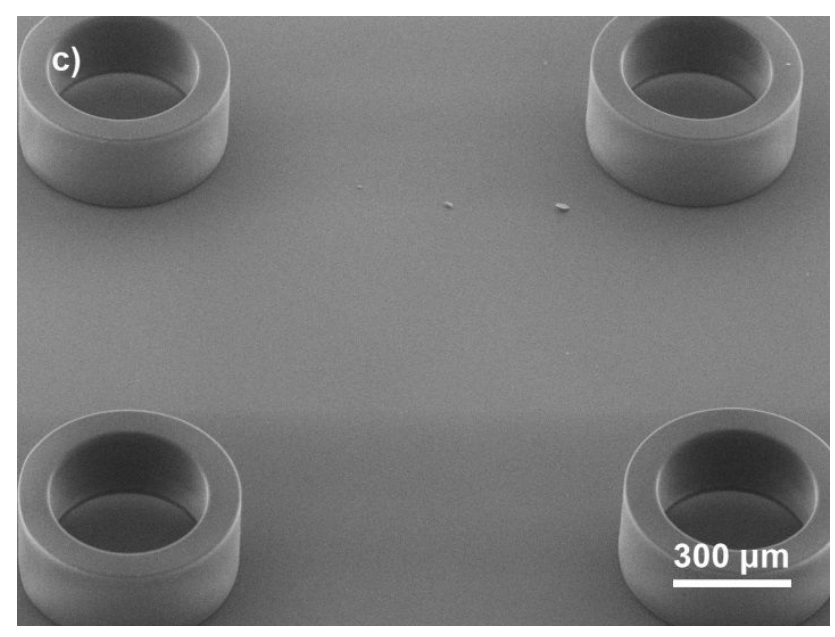

Figure 1. SEM images of SU-8 microcontainers in the size of a) small, b) medium and c) large having an internal diameter of $97 \pm 6 \mu \mathrm{m}, 191 \pm 9 \mu \mathrm{m}$ and $413 \pm 5 \mu \mathrm{m}$, respectively.

\subsubsection{LOADING OF KETOPROFEN OR NAPROXEN INTO MICROCONTAINERS} USING SUPERCRITICAL CO 2 IMPREGNATION

Every chip was manually filled with approximately $0.9 \mathrm{mg}$ of PVP powder (Figure 2a), the amount varied slightly for the different sizes (Table 2). Followed by filling with PVP, one chip per size was then simultaneously loaded with ketoprofen or naproxen. An SEM image of the medium size microcontainers after $\mathrm{scCO}_{2}$ impregnation with ketoprofen can be seen in Figure 2b. In a previous study, the amount of PVP filled per chip was higher. ${ }^{14}$ This is due to the fact that, even if the medium size microcontainers have similar dimensions to that used in the previously reported study, the number of microcontainers is here reduced from 625 to 256 . 

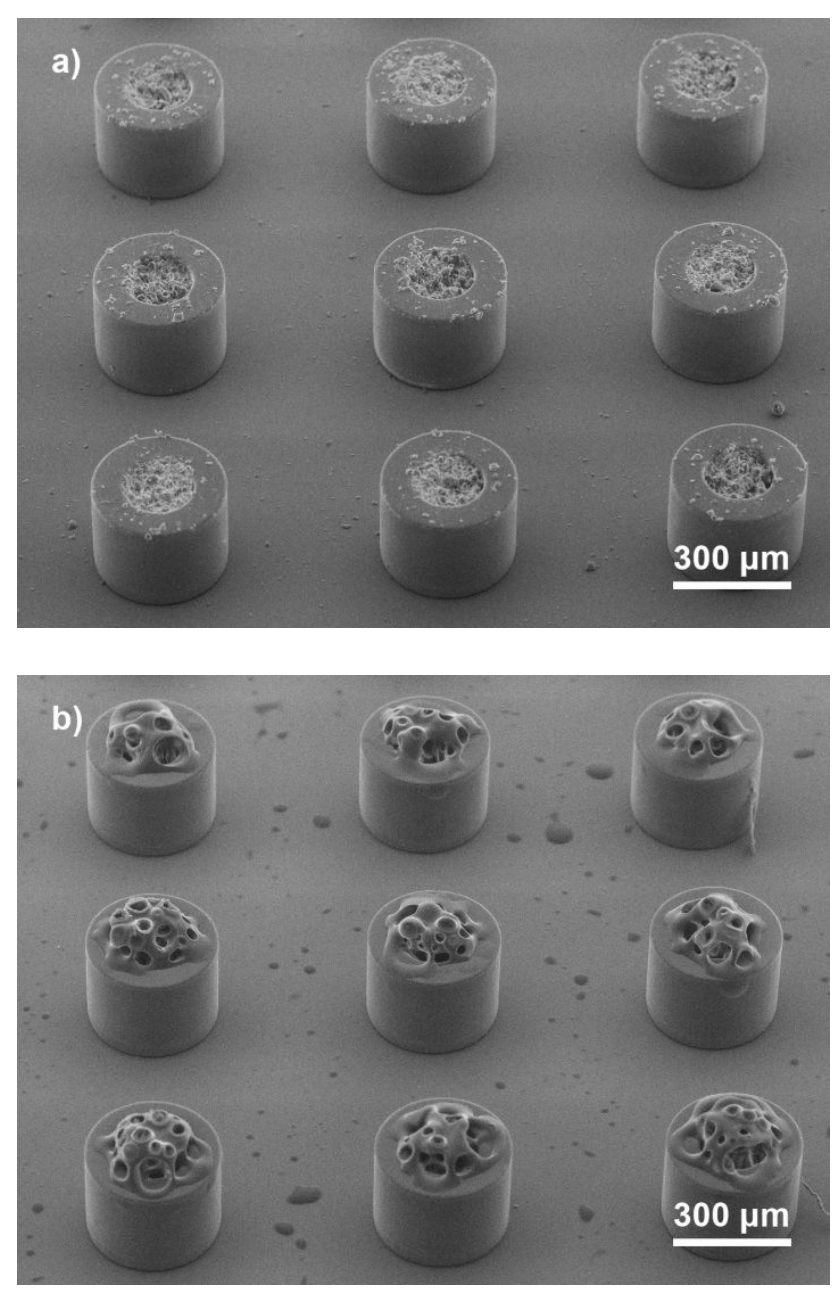

Figure 2. SEM images of medium sized microcontainers a) filled with PVP and b) loaded with ketoprofen using $\mathrm{scCO}_{2}$ impregnation. These images are representative examples of the PVP filling and the drug loading with the supercritical impregnation method.

\subsubsection{IN VITRO RELEASE OF KETOPROFEN OR NAPROXEN FROM MICROCONTAINERS}

The quantity of ketoprofen or naproxen loaded into the microcontainers with different sizes was evaluated in order to assess if there was an influence of the dimension of the surface exposed to $\mathrm{scCO}_{2}$. The quantity of the loaded ketoprofen or naproxen in small, medium or large microcontainers was obtained from the release studies (Table 2 and Figure 3). The release profiles of the small, medium and large microcontainers loaded with ketoprofen showed similar 
release profiles without any significant differences (Figure 3a). The same behavior was observed in the case of naproxen (Figure $3 b$ ).

The total amount of ketoprofen loaded in the small size microcontainers compared to the medium and large microcontainers was not significantly different (p-value: 0.4049 and p-value: 0.3667, respectively). No significant difference was observed between the loaded quantity of ketoprofen in the medium and in the large microcontainers (p-value: 0.8098). The same similarities, as observed for ketoprofen, were found for the total amount of loaded naproxen. In fact, the amount of naproxen in the small size microcontainer was not statistically different to the amount of drug in the medium or large microcontainers (p-value: 0.1071 and p-value: 0.2431 , respectively). Comparing the medium with the large size microcontainers, the total amount of loaded naproxen also did not result in statistically different drug loadings ( $p$-value $=0.3286$ )

Since the solubility of the two drugs in the $\mathrm{scCO}_{2}$ was set to be the same, the release experiments allowed for comparison of loading the two poorly water-soluble drugs into the microcontainers with three different sizes. Within the first $10 \mathrm{~min}, 90 \%$ of ketoprofen or naproxen was released (Figure 3) from all sizes of microcontainers even if the release from small microcontainers loaded with naproxen showed a larger variability. No statistical difference in the loaded amount of ketoprofen or naproxen was discernible, independent of the size of the microcontainers. Comparing the loaded amount of ketoprofen and naproxen in small microcontainer sizes, the p-value was equal to 0.4374 . For medium and large microcontainer sizes, the p-values corresponded to 0.0642 and 0.1351 , respectively.

Consequently, there was no difference in loading a BCS class II drug such as ketoprofen or naproxen in a polymer matrix (PVP) having smaller or larger surfaces exposed to the $\mathrm{scCO}_{2}$. 
This suggests that the size of the microcontainer opening has no influence on the quantity of drug loaded into the microcontainers. Furthermore, both BCS class II drugs were released with similar kinetics from the different sizes of microcontainers.

Table 2. Amount of ketoprofen or naproxen loaded in the three different sizes of microcontainers. The data represents mean $\pm \mathrm{SD}$ in triplicates.

\begin{tabular}{|l|l|l|l|}
\hline & $\begin{array}{l}\text { Amount of PVP } \\
\text { filled per chip } \\
{[\mathrm{mg}]}\end{array}$ & $\begin{array}{l}\text { Total amount of } \\
\text { ketoprofen } \\
\text { loaded per chip } \\
{[\mu \mathrm{g}]}\end{array}$ & $\begin{array}{l}\text { Total amount of } \\
\text { naproxen } \\
\text { loaded per chip } \\
{[\mu \mathrm{g}]}\end{array}$ \\
\hline Small & $0.94 \pm 0.36$ & $128.3 \pm 65.9$ & $89.7 \pm 40.95$ \\
\hline Medium & $0.82 \pm 0.1$ & $91.3 \pm 20.1$ & $160.54 \pm 42.8$ \\
\hline Large & $1.03 \pm 0.17$ & $86.1 \pm 28.7$ & $128.23 \pm 26.50$ \\
\hline
\end{tabular}


a)
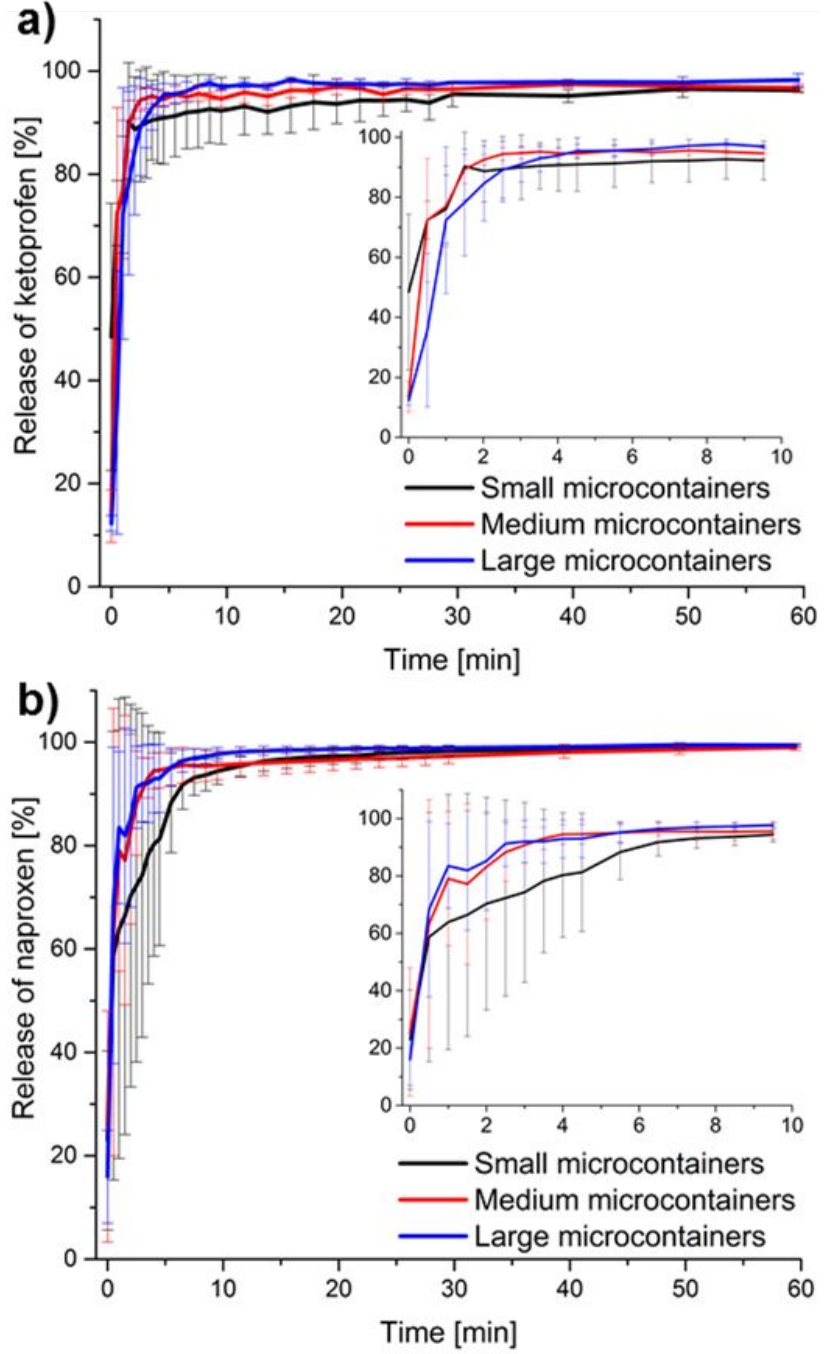

Figure 3. Release profiles of a) ketoprofen) and b) naproxen from small, medium and large microcontainers performed on a $\mu$-Diss profiler in PBS at $\mathrm{pH}$ 6.5. The inserts represent the same profiles zoomed in on the first $10 \mathrm{~min}$. The graphs represent mean $\pm \mathrm{SD}$ in triplicates.

\subsubsection{THREE-DIMENSIONAL DISTRIBUTION OF DRUGS IN MICROCONTAINERS}

It was possible to obtain 3D maps of polymer and drug-loaded microcontainers down to a depth of $225 \mu \mathrm{m}$ (the entire height of the microcontainer) using our custom-made Raman microscopy technique. To avoid heating of the sample, due to relatively high absorption of the laser, the temperature was kept constant at $8^{\circ} \mathrm{C}$. To distinguish the various materials (PVP, 
ketoprofen/naproxen, $\mathrm{SU}-8$ or $\mathrm{Si}$ ) in the samples, a chemical decomposition was performed on the spectra (Figure 4). In Figure 4, the same microcontainer 3D map reconstruction is shown in three different perspectives: an overview, a cross section view and a top view.

For all sizes of microcontainers loaded with either ketoprofen or naproxen, the drug was mainly impregnated in the top layers of the polymer matrix confined within the microcontainer walls. The results obtained in the in vitro release studies showed that both drugs reached $90 \%$ of release within $10 \mathrm{~min}$. The fast release could be explained by the fact that the drugs were mostly in the top part of the polymer matrix and not deep inside the microcontainer cavity. It is important to notice that the drug was distributed with the same morphology as PVP. It can therefore be speculated that, in a more porous polymer matrix, the drug could have penetrated deeper during the supercritical impregnation. In the top view of the microcontainers, it is possible to notice that both drugs were homogenously distributed on the PVP. Furthermore, ketoprofen and naproxen were absent at the edge of the microcontainers meaning that both drugs were preferentially deposited in the PVP matrix and not in microcontainer material, SU-8. This technique can be useful to analyze polymer matrices for drug delivery in tissue engineering since the drug depth in the polymer matrix affects the release kinetic of the drug. ${ }^{29}$ A pharmaceutical application, in which this technique can also be successfully used, is the characterization of tablet coatings as the presence of holes or different thicknesses can change the solubility kinetics of the tablet. ${ }^{30}$ 


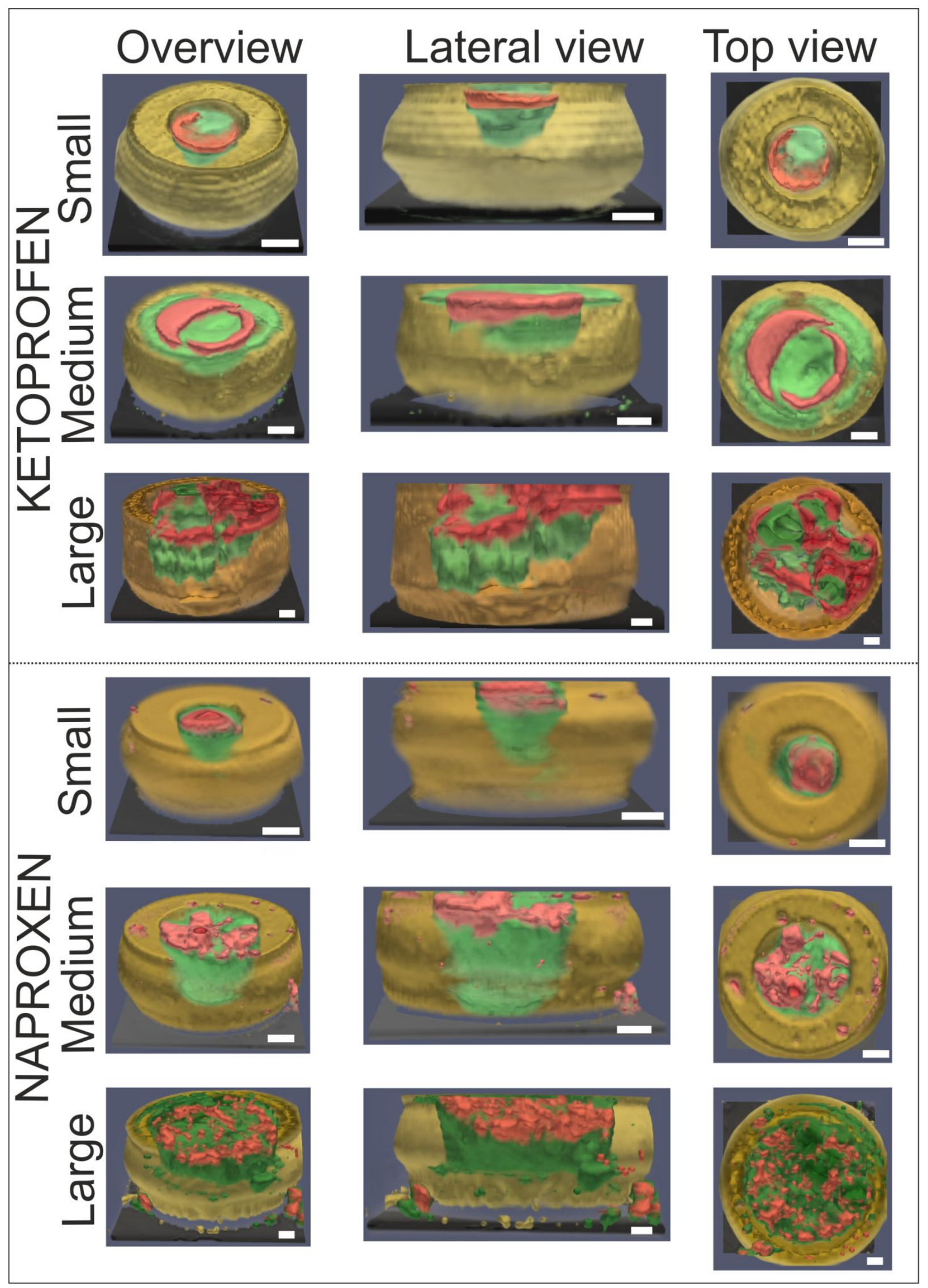


Figure 4. Volumetric Raman maps of ketoprofen or naproxen loaded into the microcontainers. The overview, the lateral view and the top view can be seen from left to right for each of the different sizes of microcontainers: small, medium and large from top to bottom. Ketoprofen or naproxen are represented in red, PVP in green, SU-8 in yellow and Si in black. The scale bars correspond to $50 \mu \mathrm{m}$.

\subsubsection{SOLID STATE ANALYSES OF THE DRUGS LOADED INTO MICROCONTAINERS}

It has previously been shown that loading ketoprofen in a PVP matrix led to its conversion into its amorphous form. ${ }^{14,18}$ In Figure 5a, the diffractograms from XRPD of the small, medium and large size of microcontainers loaded with ketoprofen showed a halo, distinctive of an amorphous form. This indicated that the loaded ketoprofen was amorphous. In the case of naproxen loaded into the PVP matrix in the different sizes of microcontainer, the diffractograms also showed a halo for the small microcontainers (Figure 5b). For the medium and large microcontainers, the halo still appeared, but with few peaks comparable to those of the crystalline diffractogram of naproxen. Probably, a low crystallization of the drug occurred in the medium and large microcontainers. In literature, studies have showed that when naproxen has been combined with excipients or other drugs, a stable amorphous form could be obtained 6,31 despite the high tendency of naproxen to recrystallize. ${ }^{32}$ In particular, Liu et al. showed that naproxen was amorphous even after 4 months when it was thermally treated and combined with PVP. ${ }^{6}$ A connection between the microcontainers size and the stability of the amorphous form of naproxen may therefore exist. This confirms what has previously been shown: smaller sizes of microcontainers prolong the stability of the amorphous form of indomethacin (BCS class II $\operatorname{drug}) .^{5}$ 

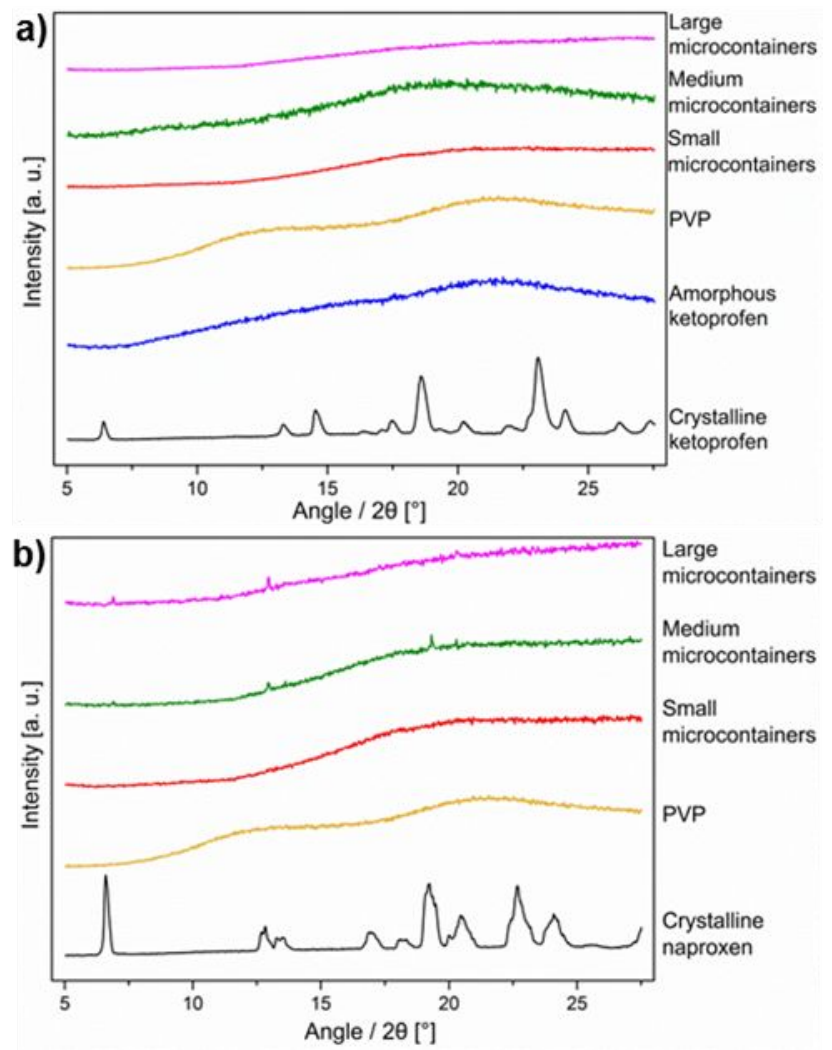

Figure 5. (a) XRPD diffractograms of crystalline and amorphous ketoprofen, PVP, small, medium and large microcontainers filled with PVP followed by impregnation with ketoprofen. (b) XRPD diffractograms of crystalline naproxen, PVP, small, medium and large microcontainers filled with PVP followed by impregnation with naproxen.

The results obtained by means of XRPD were confirmed by Raman spectroscopy for both drugs (Figure 6). The spectra from the microcontainers loaded with ketoprofen were similar to an amorphous ketoprofen spectrum, confirming that ketoprofen is amorphous when loaded in PVP matrices by $\mathrm{scCO}_{2}$ impregnation (Figure 6a). ${ }^{14}$ Due to the instability of naproxen, it was not possible to obtain a Raman spectrum of its amorphous form. Therefore, the peak-shifts were analyzed (Figure 6b). In particular, the peaks at 1626, 1390 and $740 \mathrm{~cm}^{-1}$ in the crystalline naproxen spectrum are shifted to $1630-1632,1387-1389$ and $742 \mathrm{~cm}^{-1}$ in the spectra corresponding to microcontainers loaded with naproxen meaning that naproxen loaded in the 
microcontainers is not in its crystalline form. The Raman signal from large microcontainers loaded with naproxen, at the wavenumber of $740 \mathrm{~cm}^{-1}$, showed a larger peak shift compared to the other sizes of microcontainers (Figure $6 \mathrm{~b}$ zoom-in). This might be due to the fact that the Raman spectra were acquired from a random spot within a microcontainer in which also the contribution from other materials might be measured. Previously, the same peak-shifts have been considered, together with other techniques, to show the amorphous state of naproxen when co-milled with cimetidine..$^{33}$
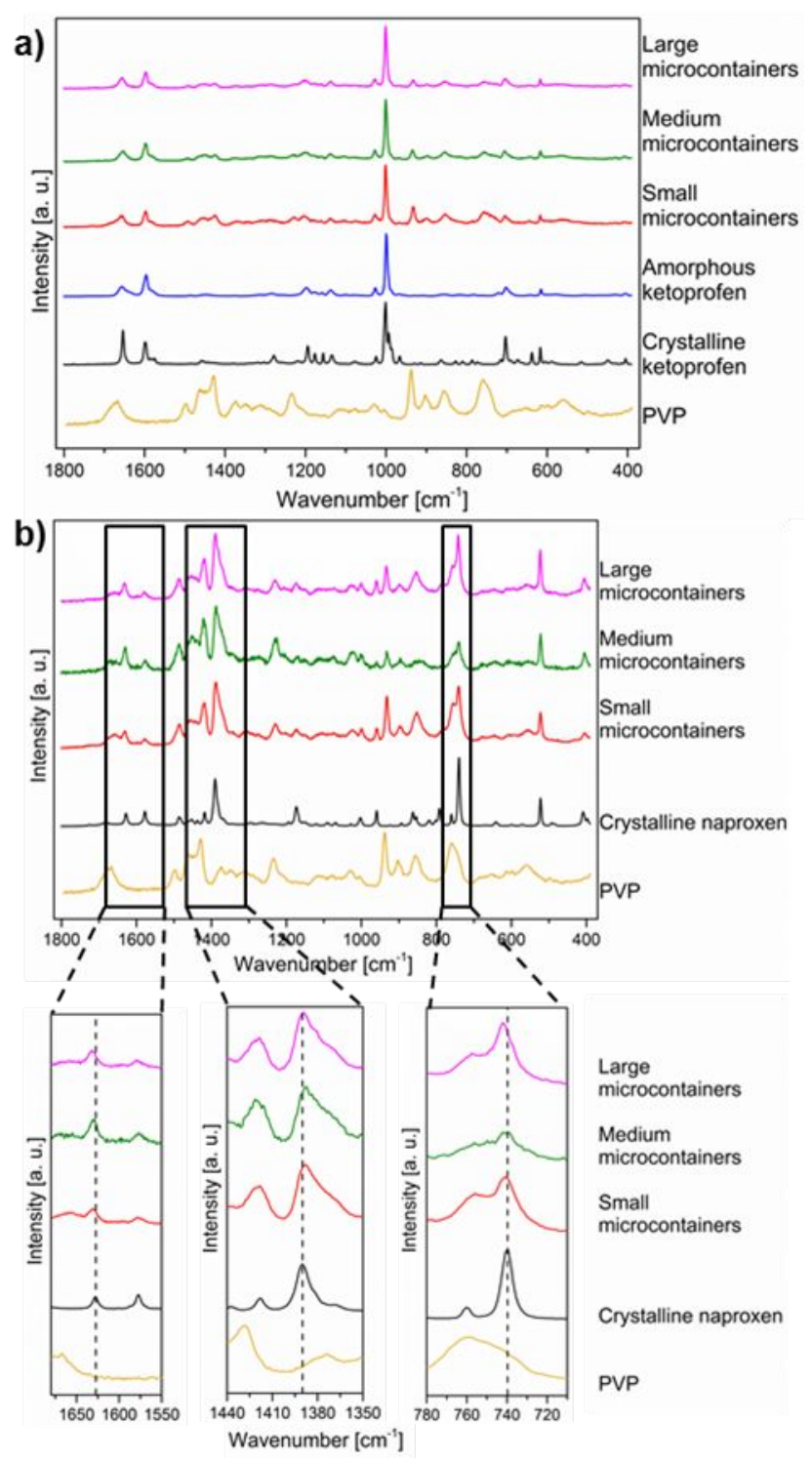
Figure 6. a) Raman spectra of PVP, crystalline and amorphous ketoprofen, small, medium and large microcontainers filled with PVP followed by impregnation with ketoprofen. b) Raman spectra of PVP, crystalline naproxen, small, medium and large microcontainers filled with PVP followed by impregnation with naproxen. The zoom-in areas show the peak-shifts in naproxen loaded in microcontainers compared to its crystalline form.

\section{CONCLUSIONS}

In this study, the influence of the surface exposed to $\mathrm{scCO}_{2}$ was evaluated when loading two poorly water soluble drugs in a PVP polymer matrix confined in microcontainers. The release studies showed that the amount of loaded naproxen or ketoprofen was the same, when keeping the total surface area constant, and the release profiles were similar having $90 \%$ of the drug released within $10 \mathrm{~min}$. For microcontainers of different sizes, the loaded amount of drug nicely correlated with the surface area of the PVP matrix exposed to supercritical $\mathrm{CO}_{2}$ during impregnation. To evaluate the 3D distribution of the drug in the polymer matrix in the microcontainers, a custom-made Raman microscope allowed obtaining volumetric Raman maps of the complete microcontainer volume. In the small, medium and large microcontainers, ketoprofen or naproxen were impregnated in the top of the polymer matrix explaining the fast release observed in the release studies. Moreover, the solid state form of the drugs was evaluated, showing that ketoprofen was amorphous in all microcontainers sizes and naproxen, despite its instability, was found only to be partly crystalline.

\section{SUPPLEMENTARY INFORMATION}

In the supplementary information, SEM images of microcontainers are shown. In Figure S1, SEM images of small and large microcontainers filled with PVP are presented, and SEM images 
of the different sizes of microcontainers loaded by $\mathrm{scCO}_{2}$ impregnation with either ketoprofen or naproxen are represented in Figure S2 and S3, respectively.

\section{ACKNOWLEDGMENTS}

The authors would like to acknowledge the Danish National Research Foundation (DNRF122) and Villum Fonden (Grant No. 9301) for Intelligent Drug Delivery and Sensing Using Microcontainers and Nanomechanics (IDUN). Nanna Bild, DTU Nanotech, is acknowledged for the drawings of the graphical abstract.

\section{REFERENCES}

(1) Tibbitt, M. W.; Dahlman, J. E.; Langer, R. Emerging Frontiers in Drug Delivery. J. Am. Chem. Soc. 2016, 138 (3), 704-717. https://doi.org/10.1021/jacs.5b09974.

(2) Amidon, G. L.; Lennernäs, H.; Shah, V. P.; Crison, J. R. A Theoretical Basis for a Biopharmaceutic Drug Classification: The Correlation of in Vitro Drug Product Dissolution and in Vivo Bioavailability. Pharm. Res. 1995, 12 (3), 413-420. https://doi.org/http://dx.doi.org/10.1023/A:1016212804288.

(3) Davis, M.; Walker, G. Recent Strategies in Spray Drying for the Enhanced Bioavailability of Poorly Water-Soluble Drugs. J. Control. Release 2018, 269, 110-127. https://doi.org/10.1016/J.JCONREL.2017.11.005.

(4) Grohganz, H.; Priemel, P. A.; Löbmann, K.; Nielsen, L. H.; Laitinen, R.; Müllertz, A.; Van den Mooter, G.; Rades, T. Refining Stability and Dissolution Rate of Amorphous Drug Formulations. Expert Opin. Drug Deliv. 2014, 11 (6), 977-989. https://doi.org/10.1517/17425247.2014.911728. 
(5) Nielsen, L. H.; Keller, S. S.; Gordon, K. C.; Boisen, A.; Rades, T.; Müllertz, A. Spatial Confinement Can Lead to Increased Stability of Amorphous Indomethacin. Eur. J. Pharm. Biopharm. 2012, 81 (2), 418-425. https://doi.org/10.1016/j.ejpb.2012.03.017.

(6) Liu, X.; Zhou, L.; Zhang, F. Reactive Melt Extrusion To Improve the Dissolution Performance and Physical Stability of Naproxen Amorphous Solid Dispersions. Mol. Pharm. 2017, 14 (3), 658-673. https://doi.org/10.1021/acs.molpharmaceut.6b00960.

(7) Petry, I.; Löbmann, K.; Grohganz, H.; Rades, T.; Leopold, C. S. Undesired CoAmorphisation of Indomethacin and Arginine during Combined Storage at High Humidity Conditions. Int. J. Pharm. 2018, $544 \quad$ (1), 172-180. https://doi.org/10.1016/J.IJPHARM.2018.04.026.

(8) Ting, J. M.; Porter, W. W.; Mecca, J. M.; Bates, F. S.; Reineke, T. M. Advances in Polymer Design for Enhancing Oral Drug Solubility and Delivery. Bioconjug. Chem. 2018, 29 (4), 939-952. https://doi.org/10.1021/acs.bioconjchem.7b00646.

(9) Nielsen, L. H.; Keller, S. S.; Boisen, A.; Müllertz, A.; Rades, T. A Slow Cooling Rate of Indomethacin Melt Spatially Confined in Microcontainers Increases the Physical Stability of the Amorphous Drug without Influencing Its Biorelevant Dissolution Behaviour. Drug Deliv. Transl. Res. 2014, 4 (3), 268-274. https://doi.org/10.1007/s13346-013-0166-7.

(10) Fox, C. B.; Cao, Y.; Nemeth, C. L.; Chirra, H. D.; Chevalier, R. W.; Xu, A. M.; Melosh, N. A.; Desai, T. A. Fabrication of Sealed Nanostraw Microdevices for Oral Drug Delivery. ACS Nano 2016, 10 (6), 5873-5881. https://doi.org/10.1021/acsnano.6b00809.

(11) Fox, C. B.; Nemeth, C. L.; Chevalier, R. W.; Cantlon, J.; Bogdanoff, D. B.; Hsiao, J. C.; 
Desai, T. A. Picoliter-Volume Inkjet Printing into Planar Microdevice Reservoirs for Low-Waste, High-Capacity Drug Loading. Bioeng. Transl. Med. 2017, 2 (1), 9-16. https://doi.org/10.1002/btm2.10053.

(12) Nielsen, L. H.; Nagstrup, J.; Gordon, S.; Keller, S. S.; Østergaard, J.; Rades, T.; Müllertz, A.; Boisen, A. PH-Triggered Drug Release from Biodegradable Microwells for Oral Drug Delivery. Biomed. Microdevices 2015, 17 (3), 1-7. https://doi.org/10.1007/s10544-0159958-5.

(13) Nielsen, L. H.; Melero, A.; Keller, S. S.; Jacobsen, J.; Garrigues, T.; Rades, T.; Müllertz, A.; Boisen, A. Polymeric Microcontainers Improve Oral Bioavailability of Furosemide. Int. J. Pharm. 2016, 504 (1-2), 98-109. https://doi.org/10.1016/J.IJPHARM.2016.03.050.

(14) Mazzoni, C.; Tentor, F.; Strindberg, S. A.; Nielsen, L. H.; Keller, S. S.; Alstrøm, T. S.; Gundlach, C.; Müllertz, A.; Marizza, P.; Boisen, A. From Concept to in Vivo Testing: Microcontainers for Oral Drug Delivery. J. Control. Release 2017, 268 (September), 343351. https://doi.org/10.1016/j.jconrel.2017.10.013.

(15) Kikic, I.; Vecchione, F. Supercritical Impregnation of Polymers. Curr. Opin. Solid State Mater. Sci. 2003, 7 (4-5), 399-405. https://doi.org/10.1016/J.COSSMS.2003.09.001.

(16) Champeau, M.; Thomassin, J.-M.; Tassaing, T.; Jérôme, C. Drug Loading of Polymer Implants by Supercritical CO2 Assisted Impregnation: A Review. J. Control. Release 2015, 209, 248-259. https://doi.org/10.1016/J.JCONREL.2015.05.002.

(17) Marizza, P.; Pontoni, L.; Rindzevicius, T.; Alopaeus, J. F.; Su, K.; Zeitler, J. A.; Keller, S. S.; Kikic, I.; Moneghini, M.; De Zordi, N.; et al. Supercritical Impregnation of Polymer 
Matrices Spatially Confined in Microcontainers for Oral Drug Delivery: Effect of Temperature, Pressure and Time. J. Supercrit. Fluids 2016, 107, 145-152. https://doi.org/10.1016/j.supflu.2015.08.023.

(18) Marizza, P.; Keller, S. S.; Müllertz, A.; Boisen, A. Polymer-Filled Microcontainers for Oral Delivery Loaded Using Supercritical Impregnation. J. Control. Release 2014, 173, 19. https://doi.org/10.1016/j.jconrel.2013.09.022.

(19) Cardea, S.; Scognamiglio, M.; Reverchon, E. Supercritical Fluid Assisted Process for the Generation of Cellulose Acetate Loaded Structures, Potentially Useful for Tissue Engineering Applications. Mater. Sci. Eng. C 2016, 59, 480-487. https://doi.org/10.1016/J.MSEC.2015.10.053.

(20) Slater, T. J.; Lewis, E. A.; Haigh, S. J. Energy Dispersive X-Ray Tomography for 3D Elemental Mapping of Individual Nanoparticles. J. Vis. Exp 2016, No. 113, 52815. https://doi.org/10.3791/52815.

(21) Sanchez, D. F.; Simionovici, A. S.; Lemelle, L.; Cuartero, V.; Mathon, O.; Pascarelli, S.; Bonnin, A.; Shapiro, R.; Konhauser, K.; Grolimund, D.; et al. 2D/3D Microanalysis by Energy Dispersive X-Ray Absorption Spectroscopy Tomography. Sci. Rep. 2017, 7 (1), 16453. https://doi.org/10.1038/s41598-017-16345-x.

(22) Trenfield, S. J.; Goyanes, A.; Telford, R.; Wilsdon, D.; Rowland, M.; Gaisford, S.; Basit, A. W. 3D Printed Drug Products: Non-Destructive Dose Verification Using a Rapid Pointand-Shoot Approach. Int. J. Pharm. 2018, $549 \quad$ (1-2), 283-292. https://doi.org/10.1016/J.IJPHARM.2018.08.002. 
(23) Cerea, M.; Maroni, A.; Palugan, L.; Bellini, M.; Foppoli, A.; Melocchi, A.; Zema, L.; Gazzaniga, A. Novel Hydrophilic Matrix System with Non-Uniform Drug Distribution for Zero-Order Release Kinetics. J. Control. Release 2018, 287, 247-256. https://doi.org/10.1016/J.JCONREL.2018.08.027.

(24) Edinger, M.; Bar-Shalom, D.; Rantanen, J.; Genina, N. Visualization and Non-Destructive Quantification of Inkjet-Printed Pharmaceuticals on Different Substrates Using Raman Spectroscopy and Raman Chemical Imaging. Pharm. Res. 2017, 34 (5), 1023-1036. https://doi.org/10.1007/s11095-017-2126-2.

(25) Ting, S. S. T.; Macnaughton, S. J.; Tomasko, D. L.; Foster, N. R. Solubility of Naproxen in Supercritical Carbon-Dioxide with and without Cosolvents. Ind. Eng. Chem. Res. 1993, 32 (7), 1471-1481. https://doi.org/Doi 10.1021/Ie00019a022.

(26) Garmroodi, A.; Hassan, J.; Yamini, Y. Solubilities of the Drugs Benzocaine, Metronidazole Benzoate, and Naproxen in Supercritical Carbon Dioxide. J. Chem. Eng. Data 2004, 49 (3), 709-712. https://doi.org/10.1021/je020218w.

(27) Ilchenko, O.; Pilgun, Y.; Makhnii, T.; Slipets, R.; Reynt, A.; Kutsyk, A.; Slobodianiuk, D.; Koliada, A.; Krasnenkov, D.; Kukharskyy, V. High-Speed Line-Focus Raman Microscopy with Spectral Decomposition of Mouse Skin. Vib. Spectrosc. 2016, 83, 180190. https://doi.org/10.1016/J.VIBSPEC.2016.02.003.

(28) Ilchenko, O. O.; Pilgun, Y. V.; Reynt, A. S.; Kutsyk, A. M. NNLS and MCR-ALS Decomposition of Raman and FTIR Spectra of Multicomponent Liquid Solutions. Ukr. J. Phys. 2016, 61 (6), 519-522. https://doi.org/10.15407/ujpe61.06.0519. 
(29) Gaikwad, V. V; Patil, A. B.; Gaikwad, M. V. Scaffolds for Drug Delivery in Tissue Engineering. Int. J. Pharm. Sci. Nanotechnol. 2008, 1 (2), 113-122.

(30) El Hagrasy, A. S.; Chang, S.-Y.; Desai, D.; Kiang, S. Raman Spectroscopy for the Determination of Coating Uniformity of Tablets: Assessment of Product Quality and Coating Pan Mixing Efficiency during Scale-Up. J. Pharm. Innov. 2006, 1 (1), 37-42. https://doi.org/10.1007/BF02784879.

(31) Beyer, A.; Grohganz, H.; Löbmann, K.; Rades, T.; Leopold, C. S. Influence of the Cooling Rate and the Blend Ratio on the Physical Stability of Co-Amorphous Naproxen/Indomethacin. Eur. J. Pharm. Biopharm. 2016, 109, 140-148. https://doi.org/10.1016/J.EJPB.2016.10.002.

(32) Sibik, J.; Löbmann, K.; Rades, T.; Zeitler, J. A. Predicting Crystallization of Amorphous Drugs with Terahertz Spectroscopy. Mol. Pharm. 2015, 12 (8), 3062-3068. https://doi.org/10.1021/acs.molpharmaceut.5b00330.

(33) Allesø, M.; Chieng, N.; Rehder, S.; Rantanen, J.; Rades, T.; Aaltonen, J. Enhanced Dissolution Rate and Synchronized Release of Drugs in Binary Systems through Formulation: Amorphous Naproxen-cimetidine Mixtures Prepared by Mechanical Activation. J. Control. Release 2009, $136 \quad$ (1), 45-53. https://doi.org/10.1016/J.JCONREL.2009.01.027. 
"For table of Contents only"

\section{Where is the drug? - Quantitative 3D distribution analyses of confined drug-loaded polymer matrices}

Chiara Mazzoni*, Fabio Tentor, Anastasia Antalaki, Rasmus D. Jacobsen, Jacob Mortensen, Roman Slipets, Oleksii Ilchenko, Stephan S. Keller, Line H. Nielsen, Anja Boisen*

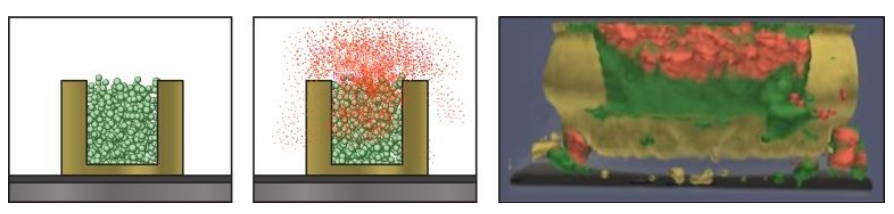

